\title{
Virtual Electron Microscopy for Undergraduate/Graduate Classes
}

\author{
Dr. Elaine Humphrey, University of British Columbia \\ The BioImaging Facility, 6270 University Blvd mailstop Botany, Vancouver, BC, V6T 1Z4, Canada
}

How do you give 1150 undergraduates in an introductory cell biology course (Biology 200) access to electron microscopes? Students often ask if they can see the electron microscopes. They often ask if they will have an opportunity to learn EM. As part of the course material, students are expected to recognize the images produced by different EM techniques, know the advantages and disadvantages of these techniques and interpret 2dimensional micrographs in 3 dimensions. This is akin to teaching the theory of baking bread without ever smelling it in the oven. A pilot project was designed to address getting round the impossibility of bringing $1150+$ students into the BioImaging Facility. This initiative gave selected undergraduates a hands-on experience of SEM in the Bioimaging Facility and allowed the rest of their classmates to share that experience.

The students were invited to hand in proposals for SEM projects at the beginning of term. The winning proposals are available on the course website. One student from each of the 5 lecture sections was to be selected (we actually chose seven). They were trained in specimen presentation and the operation of the Scanning Electron Microscope. At the end of the semester, when the students were proficient on the SEM, there was a two-way connection set up, through telepresencing, to the lecture hall. The student on the SEM explained to their classmates what they have done and how the SEM works. Students in the lecture hall saw images in real time, video streamed from the SEM via the internet, and were able to ask questions in real time. Three images were available within the SEM room: one from the SEM screen, one from the SEM chamber and one from the room showing the operator and the controls on the SEM, We caught the excitement in the real experience and the peer-to-peer contact that we have not been able to duplicate in a video tour. A mobile camera/video streaming system in the lecture theatre allowed the person operating the SEM to see their classmates via the internet and hear them in real time. This system will work in the different lecture theatres where there is internet connections. The projects and results were put onto the Bio 200 website and the Bio-Imaging website www.emlab.ubc.ca, and the images are available in the BioMedia database. Many, many students benefited from these projects; 1150 of them in Biology 200, the 5 chosen operators, and future students through access to the database. We learned a lot from one pilot project. We are now ready to enhance the project and have ideas about how to improve it.

\section{OBJECTIVES:}

Students will be stimulated and excited about the possibility of cell biology research Undergraduate students will be aware of and benefit from the EM Facility Biology 200 students will have a greater pride in their university and a greater awareness of the research environment for cell biology

\section{BUDGET:}

Most of the mobile telepresencing equipment (for the lecture theatre) was purchased with the help of a TLEF (UBC Teaching and Learning Enhancement Fund) grant. The telepresencing from the SEM came with the SEM. Supplies for specimen preparation, machine time on the SEM and salaries for the technicians to train the students and set up the telepresencing was absorbed by the BioImaging Facility budget but grants are being pursued for future projects. A more comprehensive breakdown of the costs will be given in the lecture.

This idea was initiated by talks given by Nestor Zaluzec at previous MSA meetings! We had to adapt Nestor's approach because we do not have his programming expertise. We relied on commercially available products. Even so, it was not trivial to set up and we learned a lot in our pilot. But it allows undergraduate students to gain access to a world-class research facility using a high tech approach and is well worth the effort. Some had a 
hands-on experience that is not currently available to undergraduates. They were able to share that experience with their classmates. Others had a virtual experience in real time, along with their peers.

The UBC Bio-Imaging lab is a busy, exciting place in which to work and visit. Researchers come from all over the campus and all over the world to use the equipment and take advantage of the staff expertise, training and advice. The lab has a field emission scanning electron microscope (SEM), which can reach a magnification of $500,000 \mathrm{X}$ with a resolution of about $2.5 \mathrm{~nm}$. It also has two transmission electron microscopes (TEM), a variable pressure SEM, as well as three confocal microscopes and all the equipment necessary for specimen preparation, including cryofixation, and image analysis. We have telepresencing on two of the SEMs, one TEM, one light microscope and one confocal. The confocal is not a good subject for telepresencing but the other microscopes allow graduate students to discuss their specimen with their supervisors in real time without the supervisors having to be in the facility (They could be anywhere there is an internet connection). It also allows collaboration with experts in real time anywhere in the world.

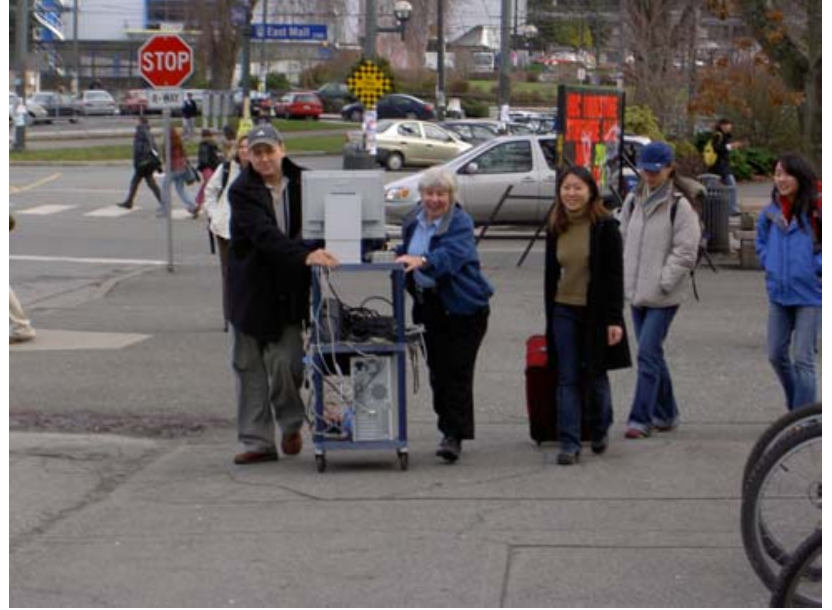

Mobile Telepresencing System

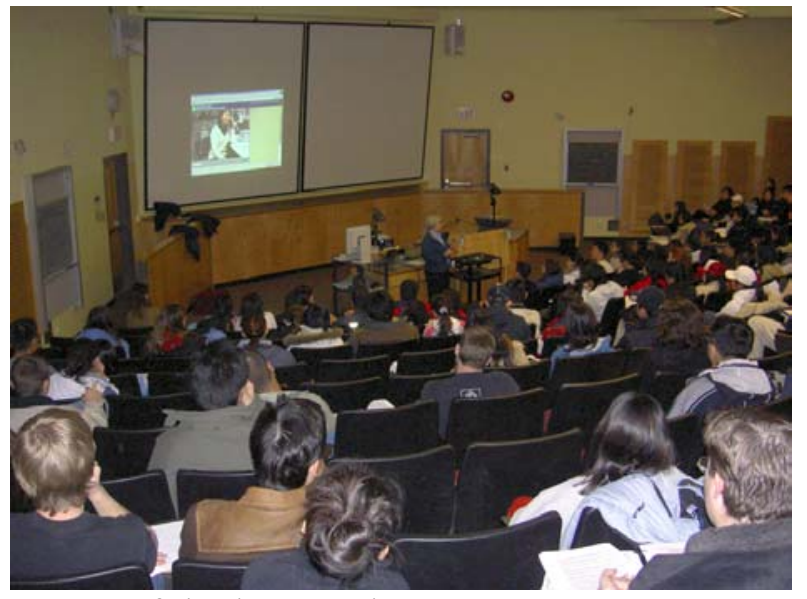

In one of the lecture theatres

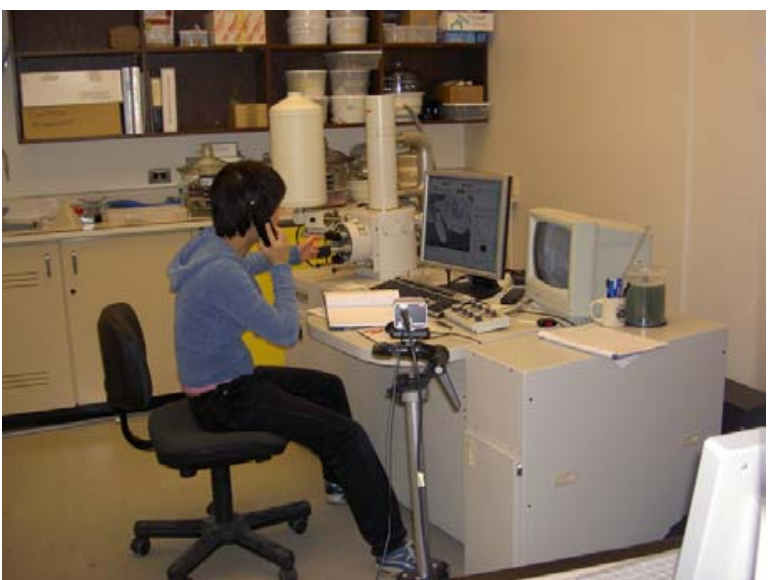

In one of the SEM rooms

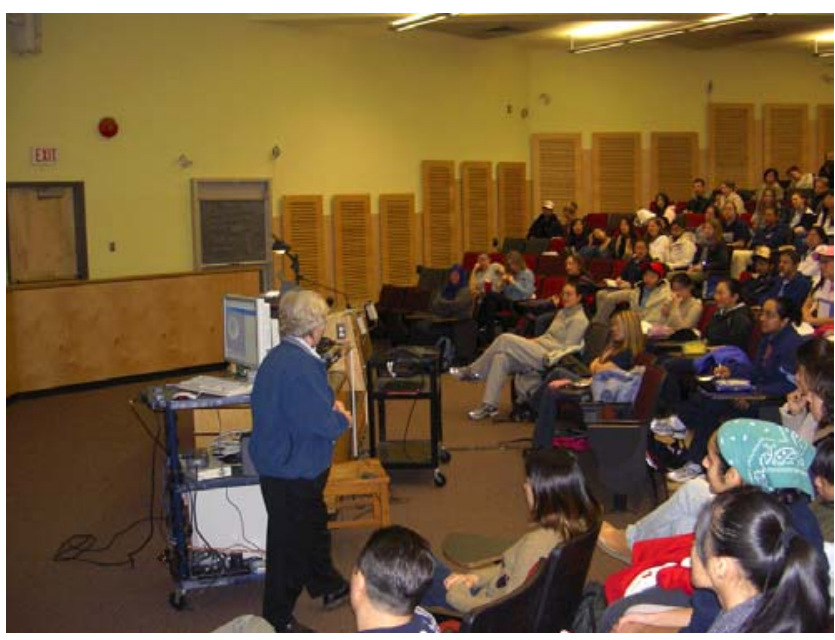

From the front of theatre with the cart 